\title{
Experimental study on the effective width of flat slab structures under dynamic seismic loading
}

\author{
Amadeo Benavent-Climent , Diego Zamora-Sánchez, José Francisco Gil-Villaverde
}

\begin{abstract}
A B S T R A C T
This paper investigates the effective width of reinforced concrete flat slab structures subjected to seismic loading on the basis of dynamic shaking table tests. The study is focussed on the behavior of corner slabcolumn connections with structural steel I- or channel-shaped sections (shearheads) as shear punching reinforcement. To this end, a $1 / 2$ scale test model consisting of a flat slab supported on four box-type steel columns was subjected to several seismic simulations of increasing intensity. It is found from the test results that the effective width tends to increase with the intensity of the seismic simulation, and this increase is limited by the degradation of adherence between reinforcing steel and concrete induced by the strain reversals caused by the earthquake. Also, significant differences are found between the effective width obtained from the tests and the values predicted by formula proposed in the literature. These differences are attributed to the stiffening effect provided by the steel profiles that constitute the punching shear reinforcement.
\end{abstract}

\section{Introduction}

Flat slabs are extensively used to resist wind and seismic forces in low-to-moderate seismicity regions such as the Mediterranean area. The behavior of this type of structural system under gravitational loads is well established. In contrast, its behavior under lateral loads is not well understood, particularly under dynamic seismic loadings. In common practice, flat slab structures with a regular distribution of columns are analyzed as two-dimensional frames in the elastic domain, applying two approaches: torsional member methods and effective slab methods. The most common procedure pertaining to the first approach is the so-called Equivalent Column Method [1]. It defines a transverse torsional spring to model the torsional stiffness of the slab adjacent to the slabcolumn connection. This torsional stiffness is combined with column stiffness to define the properties of an equivalent column. In the effective slab width method [2-12], the slab is modeled as a beam and its equivalent width is adjusted to simulate the actual behavior of the three-dimensional system, while depth remains the actual depth of the slab. The calculated effective width takes into account that the slab is not fully effective across its transverse width.

The study presented in this paper focuses on the effective slab width method, which, in contrast to the torsional member method, can be easily used with conventional frame analysis software. The effective width of the slab is calculated using normalized or conventional approximations, generally based on Finite Element Method calculations [10], and static or quasi-static experiments [11,12].

Hence, there is a need for documented experiments surrounding the equivalent width of flat slabs in the presence of realistic dynamic seismic loads. The behavior of structures under dynamic loads is not the same as under static loads, because of the influence of strain rate effects. The resistance of reinforced concrete (RC) members can increase anywhere from $7 \%$ to $20 \%$ with dynamic excitations [13].

Despite extensive work conducted in the past by numerous authors, the dynamic behavior of flat slab structures under lateral displacements is not well understood, meaning there is room for improving lateral design methods. Also scarce is research on the seismic behavior of corner slab-column connections that rely on structural steel I- or channel-shaped sections (shearheads) as shear reinforcement. Indeed, shearheads in corner connections are not specifically contemplated under the usual norms, for instance ACI Building Code [14-18] or Eurocode 2 [19]. Moreover, the contribution of this type of punching shear reinforcement (i.e. shearheads) cannot be completely included in well-known formulas for predicting effective width, such the one proposed by Grossman [9] or Luo and Durrani $[7,8]$. Grossmańs equation [9] cannot account for the effect of shearheads, while the equations proposed by Luo and Durrani $[7,8]$ only partially include the effect of shearheads by means of the critical shear area considered in the stiffness reduction factor. 
One formula proposed by Luo and Durrani is based on previous research conducted by Pecknold [2], who in 1975 developed a model of equivalent slab width in which the effective width coefficient (ratio between effective and original width) was deduced via elastic plate theory and a Levy type solution. Later, in 1977, Allen and Darvall [3] employed a Fourier series technique and published results that are concordant with Pecknold's. Despite posterior debate, Pecknold's equation was never widely accepted by engineers because it proved hardly practical.

In this context, this paper describes experimental investigation to study the effective width of RC corner flat slab-column connections with shearheads as punching reinforcement, subjected to dynamic shaking table tests. The paper discusses the predictions provided by different formulae proposed in the literature. It is observed that the effective width tends to increase with increasing values of the peak acceleration applied to the structure, and that this increase is limited by the loss of adherence between the reinforcing steel and the surrounding concrete. Also, a simple procedure is suggested for estimating the effective width on the basis of the experimental results.

\section{Experiments}

A prototype one-bay and one-story structure was designed, from which a test model was constructed and tested using the shaking table of the Laboratory of Structural Dynamics at the University of Granada, as explained below.

\subsection{Description of prototype structure}

The prototype structure consisted of a $0.25 \mathrm{~m}$ deep RC flat slab supported by four box-type steel columns. The height of the structure was $2.8 \mathrm{~m}$ and its dimensions in plan $4.8 \times 4.8 \mathrm{~m}^{2}$. In the slabcolumn connections, punching shear reinforcement (shearheads) were included. The prototype was hypothesized to be located in the most earthquake prone region of Spain (the area of Granada), where the design peak ground acceleration (PGA) according to the current Spanish seismic code [20] is $0.23 \mathrm{~g}$ ( $\mathrm{g}$ being the acceleration of gravity). The prototype was designed according to Spanish codes NCSE-02 [20], CTE [21], and EHE [22].

\subsection{Description of the test specimen}

A reduced-scale model satisfying the similitude laws was designed from the prototype structure. The test model was derived applying as scaling factors for geometry, acceleration and stress, respectively: $\lambda_{1}=1 / 2, \lambda_{a}=1$ and $\lambda_{\sigma}=1$. The test model was built in the Structural Engineering Laboratory at the University of Granada. The slab, $125 \mathrm{~mm}$ deep, was reinforced with two steel meshes, the one at the top consisting of $6 \mathrm{~mm}$ diameter bars at $100 \mathrm{~mm}$, and the one at the bottom of $6 \mathrm{~mm}$ diameter bars at $75 \mathrm{~mm}$. The punching shear reinforcement at the corners of the slab consisted of $60 \mathrm{~mm}$ deep steel C-shapes. The $\mathrm{C}$-sections were with stirrups of $6 \mathrm{~mm}$ diameter spaced $75 \mathrm{~mm}$.

Fig. 1 shows the geometry and reinforcing details. The average yield stress, $f_{s}$, of the reinforcing steel was $467 \mathrm{MPa}$, while the average concrete strength was $f_{c}=23.5 \mathrm{MPa}$. The columns were built with an $80 \times 80 \times 4 \mathrm{~mm}$ hollow-steel section. The average yield stress, $f_{y}$, of the steel used for the columns was $216 \mathrm{MPa}$. The channels and the steel columns were joined by means of arc welding. Fillet welds were used. The confining reinforcement on the C-sections consisted of $6 \mathrm{~mm}$ diameter stirrups spaced $75 \mathrm{~mm}(=0.7 d)$. There are no significant differences in shear reinforcement requirements between the Spanish concrete code EHE and the ACI 318-08 code, but it is worth noting that in the ACl-318-08 the maximum (a)

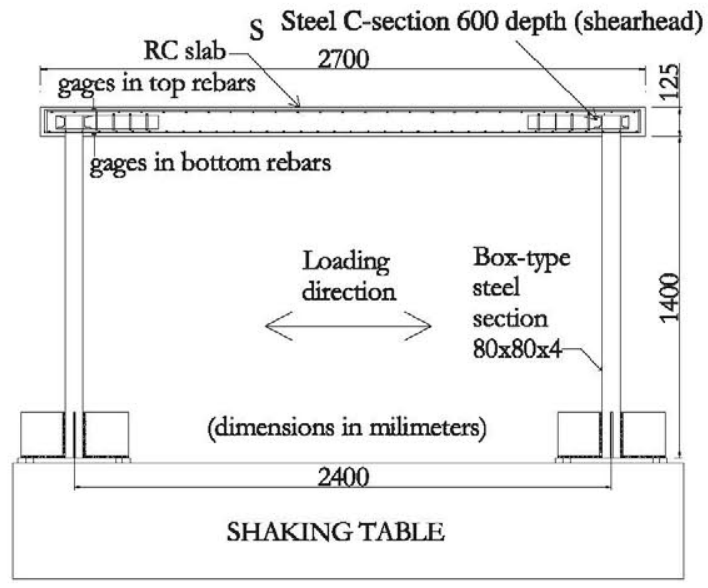

(b)

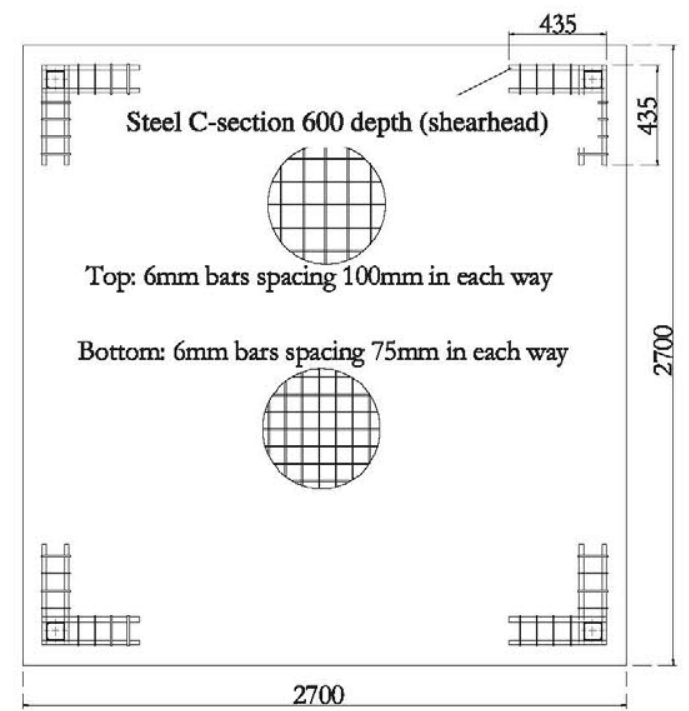

Fig. 1. Test model: (a) elevation and (b) plan (bottom view).

spacing of shear reinforcement is $0.5 d$, while in the Spanish code it ranges from $0.30 d$ to $0.75 d$ depending on the ratio between the factored shear strength demand and the nominal shear strength provided by concrete.

\subsection{Setup, seismic loading and instrumentation}

Fig. 2 describes the experimental set-up and instrumentation. Fig. 3 shows the test model just before starting the seismic simulations. The test model was bolted to the shaking table. In order to satisfy the similitude laws between prototype and test model, additional mass in form of steel blocks was added to the top of the RC slab. The total mass of the test model including the steel blocks was $m=7.39 \mathrm{~N} \mathrm{~s}^{2} / \mathrm{mm}$. The steel blocks that form the additional mass were fixed to the slab by means of short segments of Lshaped steel profiles.

During each seismic simulation, displacements, strains and accelerations were acquired simultaneously. Vertical auxiliary members consisting of L-shaped aluminum profiles were attached to the shaking table to fix the displacement transducers (LVDTs) that measured the relative horizontal displacements between the slab and the shaking table, as shown in Fig. 2. The displacement transducers labeled as LVDT 1 and LVDT 2 measured the relative displacement between the slab and the shaking table in the direction of the seismic excitations. The displacement transducer labeled as LVDT 3 measured the relative displacement between 
(a)

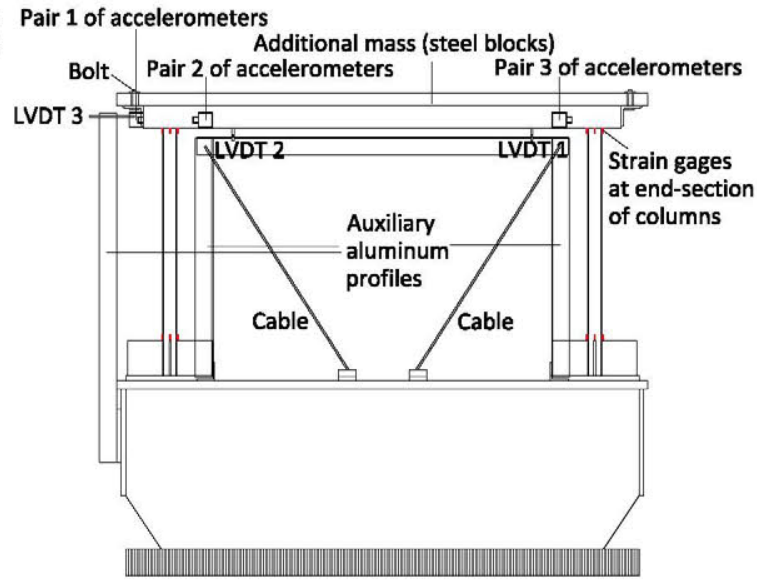

(b)

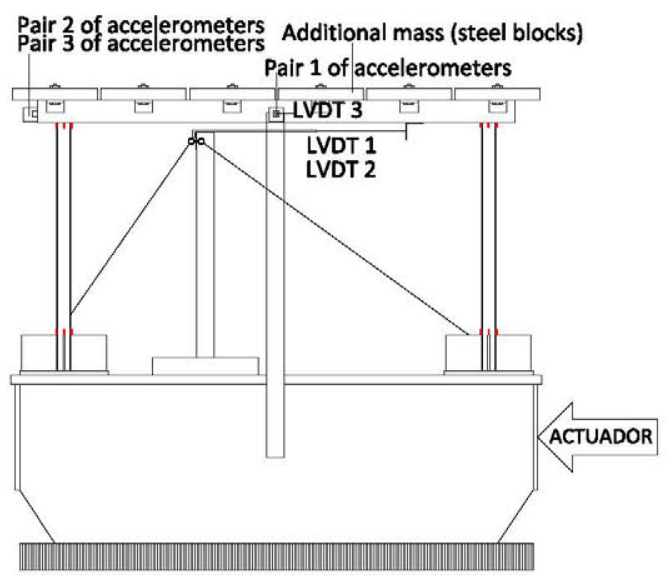

Fig. 2. Set-up: (a) elevation perpendicular to the direction of shaking and (b) elevation parallel to the direction of shaking.

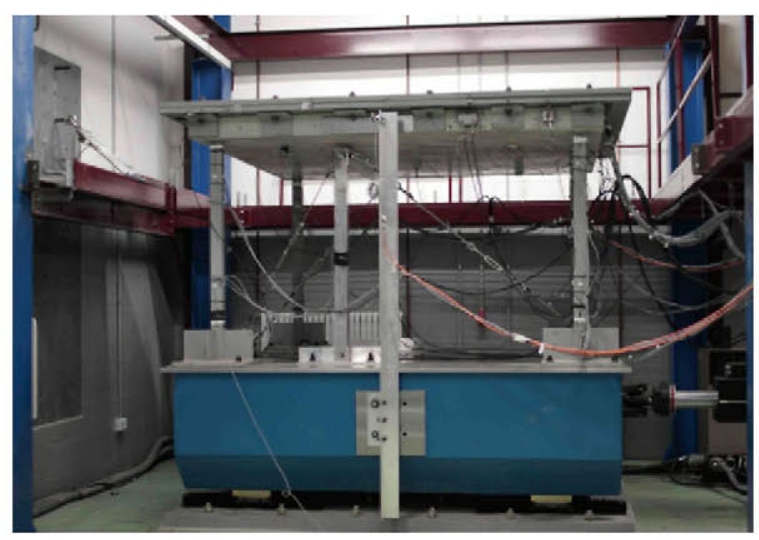

Fig. 3. Photograph of the test set-up and instrumentation.

the slab and the shaking table in the direction perpendicular to the seismic excitation. Three pairs of accelerometers were fixed at three different points of the slab as shown in Fig. 2. The accelerometers labeled "Pair 2 of accelerometers" and "Pair 3 of accelerometers" measured the horizontal acceleration in the direction of the seismic excitation. The accelerometers labeled "Pair 1 of accelerometers" measured the horizontal acceleration in the direction perpendicular to the direction of the seismic excitation. An additional accelerometer pre-installed in the shaking table measured its horizontal acceleration. Electrical resistance strain gauges were

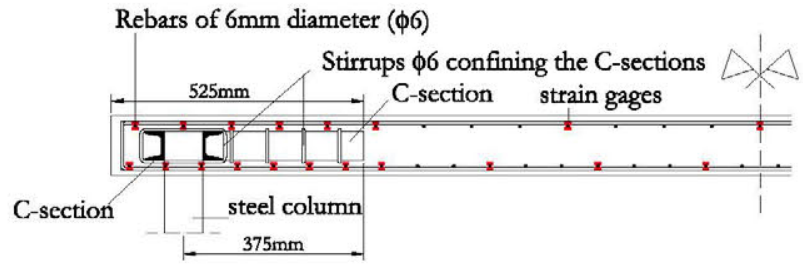

Fig. 4. Instrumentation of a section perpendicular to the direction of shaking (mm).
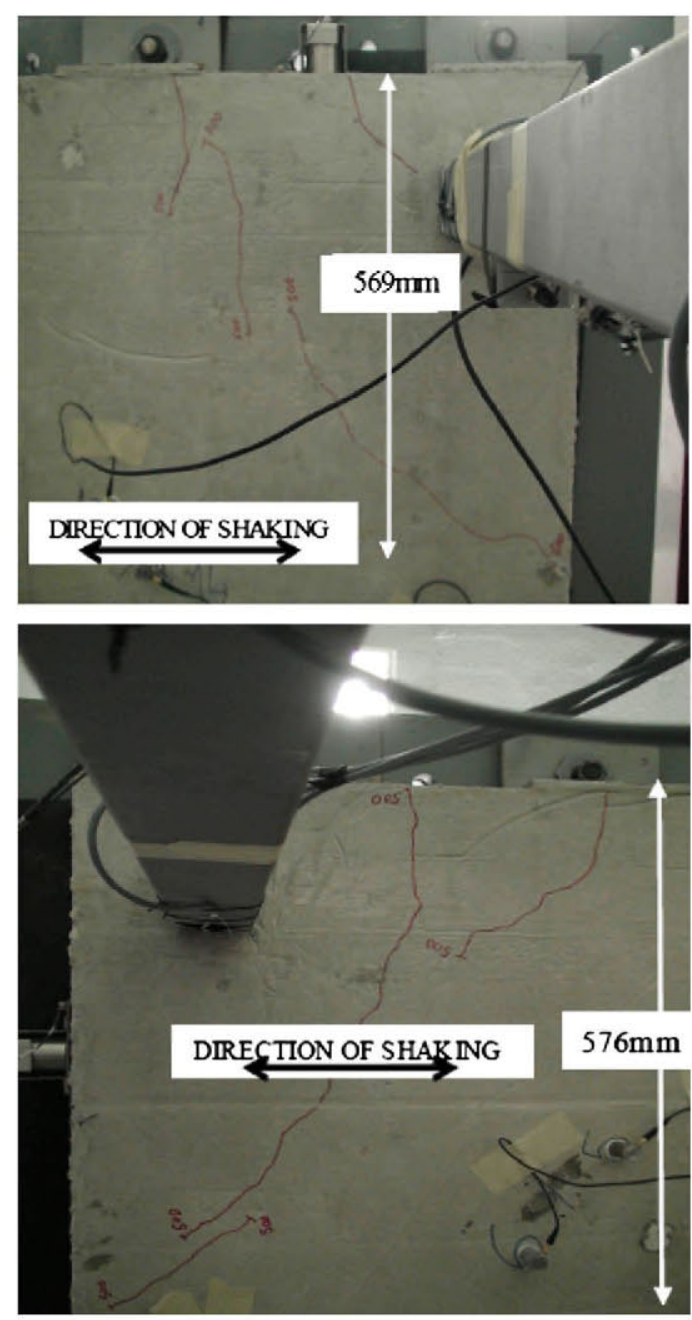

Fig. 5. Crack patterns.

attached to the top and bottom longitudinal reinforcing bars near the corner of the slab prior to casting the concrete, as indicated in Fig. 4. Strain gauges were also attached at the upper and lower ends of the columns as shown in Fig. 2. Data collection was continuous, with a sampling rate of $200 \mathrm{~Hz}$.

The test model was tested by applying the signal of the Calitri 1980 NS earthquake (Campano-Lucano, Italy). The shaking table was subjected to a series of seven consecutive seismic simulations with increasing peak accelerations (PA), namely $0.16 \mathrm{~g}, 0.31 \mathrm{~g}, 0.47 \mathrm{~g}$, $0.62 \mathrm{~g}, 0.78 \mathrm{~g}, 0.94 \mathrm{~g}$, and $1.10 \mathrm{~g}$. The original (unscaled) Calitri earthquake has a peak ground acceleration $(0.16 \mathrm{~g})$ close to typical design values prescribed by codes in the Mediterranean area. The main characteristic that makes it desirable to use for experimental work is that it has a wide window of periods (between 0.5 and $1.5 \mathrm{~s}$ approximately) where the acceleration amplification factor is about 2.5 . 


\section{Experimental results}

\subsection{Overall response}

The columns started to plastify at the top and at the bottom ends in the seismic simulation corresponding to $0.47 \mathrm{~g}$, which limited the maximum bending moment transferred from the column to the slab. The reinforcing steel of the slab did not reach its nominal yield stress in any of the seismic simulations, though it did get very close (up to approximately $90 \%$ of the yield stress). Fig. 5 shows the cracks on the concrete slab at the column locations. The cracks followed an approximately concentric pattern centered on the column, and the outermost crack was located about $570 \mathrm{~mm}$ from the corner of the slab. This slab cracking pattern is consistent with the decrease of the strains of the steel bars after about $600 \mathrm{~mm}$, as discussed in the next subsection.

\subsection{Strains in longitudinal bars}

Fig. $6 a-n$ shows the distribution of strains for all seismic simulations, in the top and bottom reinforcement of the slab. Each row
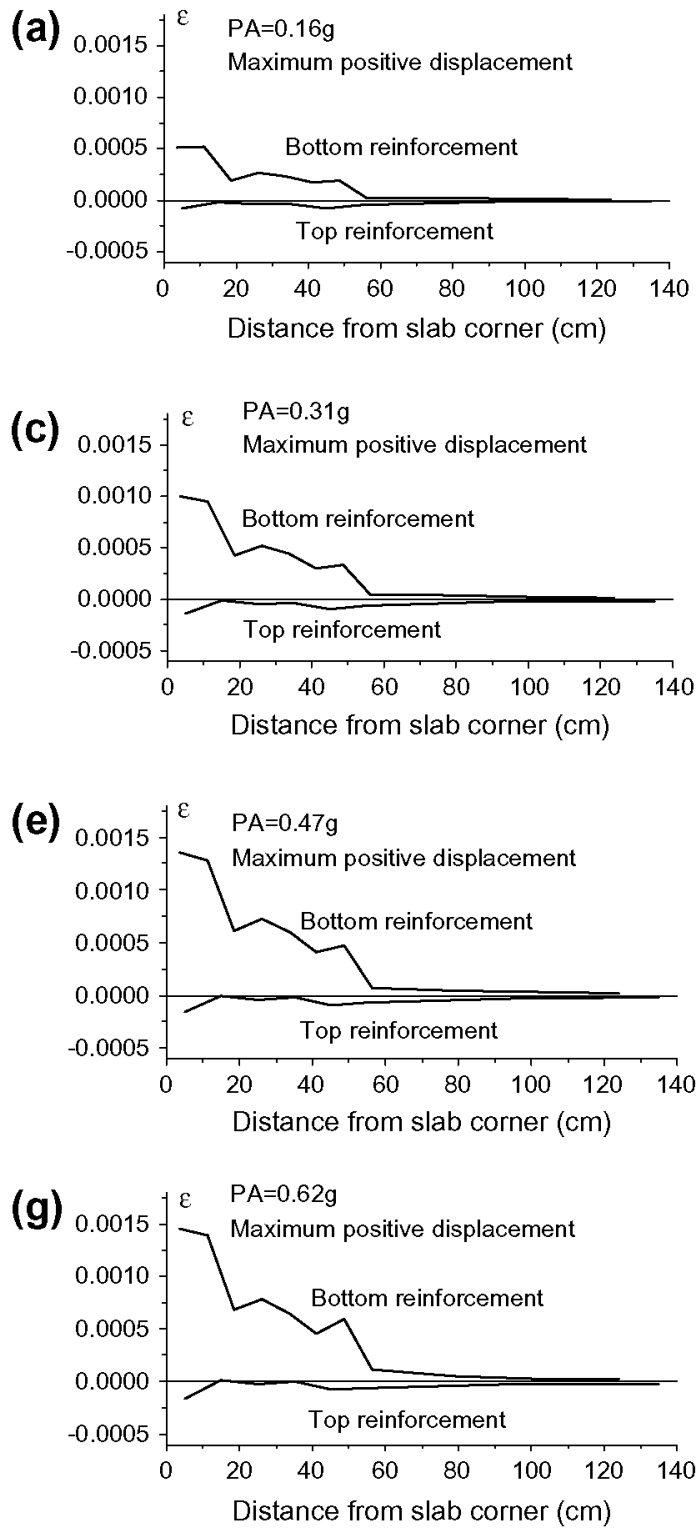

corresponds to a different seismic simulation characterized by PA. The left column of figures shows the strain distribution at the instant when the maximum lateral displacement of the slab relative to the table was reached in the positive direction. The right column of figures shows the strain distribution at the instant of maximum lateral displacement of the slab in the negative direction.

As can be observed in Fig. 6, the strains of the steel bars decrease significantly after about $600 \mathrm{~mm}$ measured from the corner of the slab. The maximum strains beyond $600 \mathrm{~mm}$ in Fig. 6l-n are less than $25 \%$ of the maximum strain measured within the $600 \mathrm{~mm}$ width. This indicates that the collaboration of the longitudinal rebars located beyond $600 \mathrm{~mm}$ from the corner of the slab in resisting the lateral actions was relatively small. This pattern on the strain distribution can be observed while the steel columns are on the elastic range (i.e. for the seismic simulations with $P A=0.16 g$ and $P A=0.32 g$ ), and also after the onset of plastification of the steel columns (i.e. the seismic simulations with PA equal or greater than $0.47 \mathrm{~g}$ )

Deserving mention in view of Fig. 6 is that in the seismic simulations with PA greater than $0.47 \mathrm{~g}$, several bars supposedly in compression according to the sign of the bending moment applied at

(b)

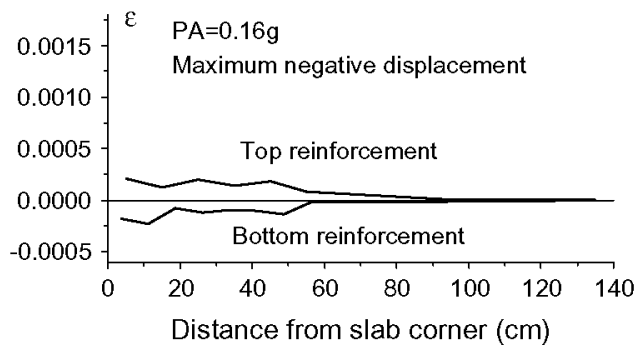

(d)

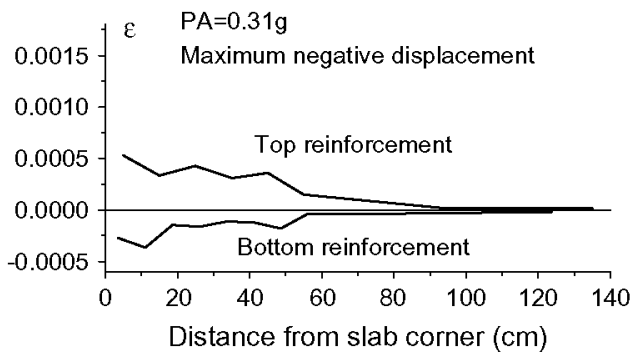

(f)

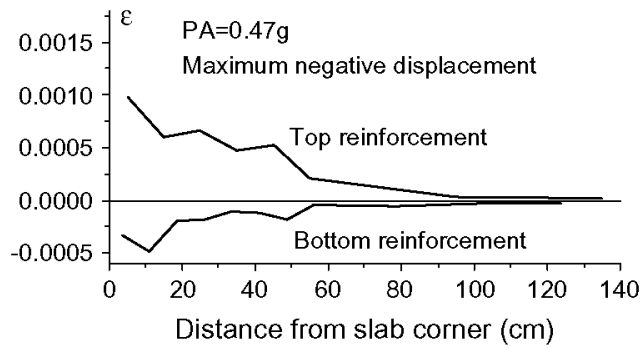

(h)

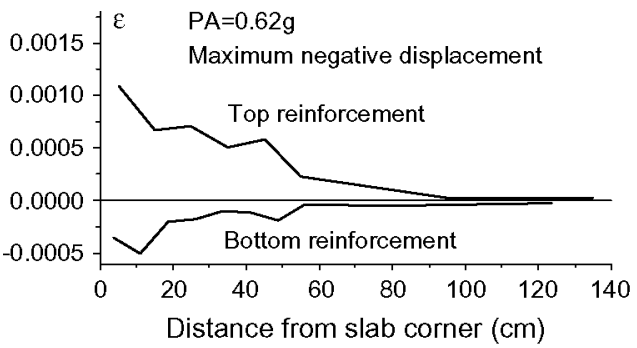

Fig. 6. Strain distribution at the instant of maximum lateral drift of the slab relative to the table, in the positive direction (left) and in the negative direction (right). 
(i)

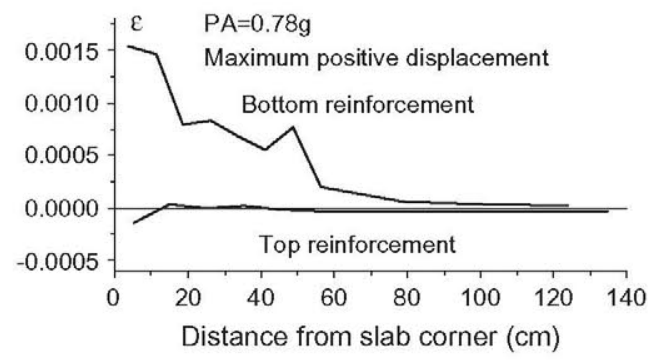

(k)

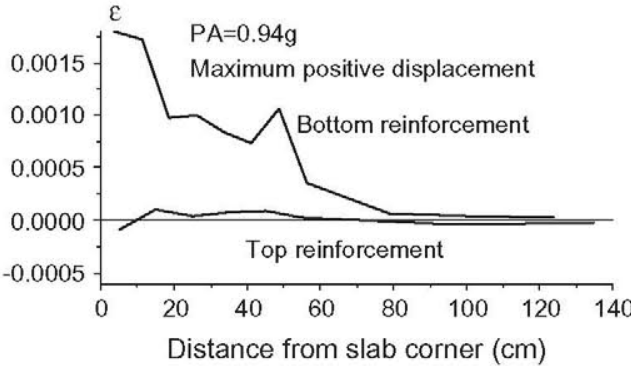

(m)

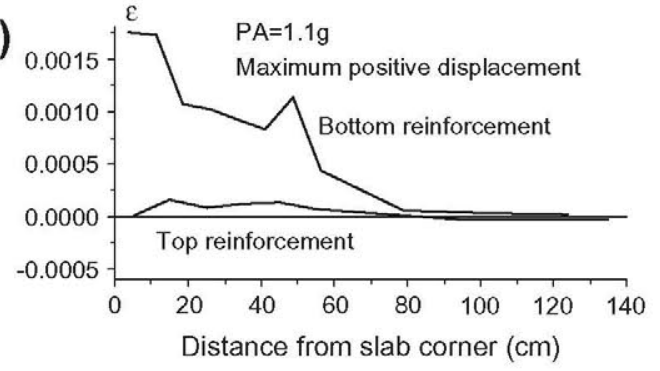

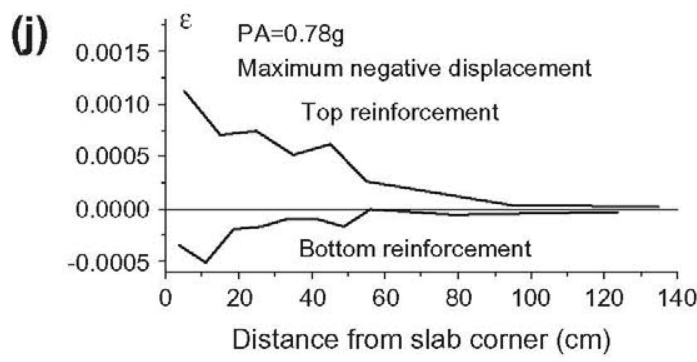

(I)

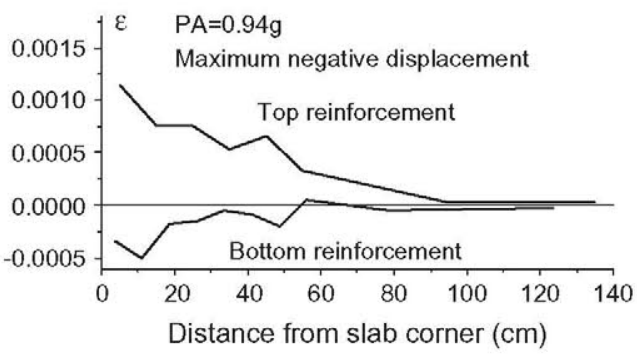

(n)

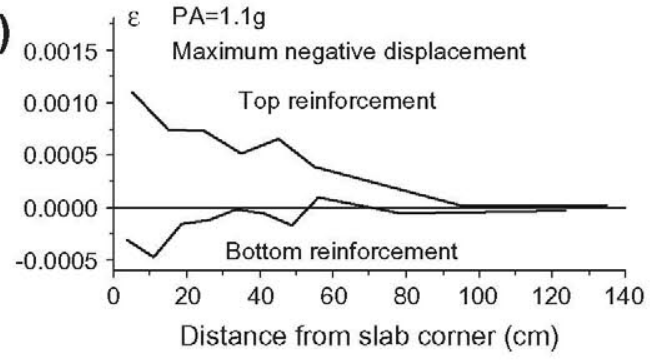

Fig. 6 (continued)

that instant, were in fact in tension. This phenomenon is attributed mainly to the loss of adherence between steel and the surrounding concrete due to bond deterioration under repeated cycles of loading. To further clarify this point, Fig. 7 plots the strains measured in the top reinforcing bar located $45 \mathrm{~cm}$ from the corner of the slab against the lateral restoring force $Q$ exerted by the structure. When $Q$ is positive the bending moment on the slab is also positive and the bar is in the compression zone. The load versus strain plot indicates that the bar experienced cyclic tension and compression dur-

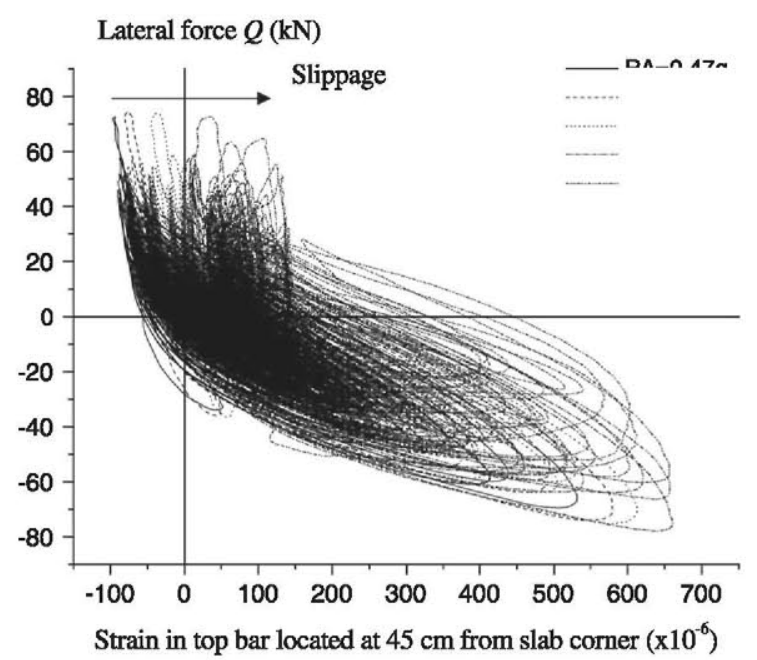

Fig. 7. Relation between strains in the top bar located $45 \mathrm{~cm}$ from the corner of the slab and the lateral restoring force exerted by the structure. ing the seismic simulations $\mathrm{PA}=0.42 \mathrm{~g}, \mathrm{PA}=0.62 \mathrm{~g}$ and $\mathrm{PA}=0.78 \mathrm{~g}$, but compressive strains were smaller and smaller as the number of seismic simulations and the number of cycles of loading applied to the slab increased. Thereafter, the beginning of slippage was obvious, as indicated by the appearance of tensile strains of increasing magnitude, when the bar was on the compression side of the slab (i.e. when $Q$ was positive). This behavior of the strain versus load curves is typical when there is loss of adherence between steel bars and surrounding concrete, and it has been observed in past experimental studies [23]. Other effects such as residual cracks caused by the crack opening and closing process and the axial forces in the concrete slab may have also affected the strain behavior of reinforcement to some extent. These effects, however, are believed to be of minor importance, because the reinforcing steel remained within the elastic range, and the width of the cracks and level of the axial forces acting on the slab were small.

The effect is more exacerbated in the top rebars than in the bottom ones, probably owing to the concrete casting process that results in worse adherence conditions for the upper bars than for lower bars, and to the lower amount of reinforcement at the top slab mesh. As a result, the contribution of the compressed reinforcing steel for sustaining the maximum bending moment transferred by the column is smaller under positive bending than under negative bending moments.

Consequently, for similar absolute values of the maximum moments under positive and negative bending, and for similar ratios of the top and bottom reinforcement, the strains that need to be developed by the tension reinforcement become larger under positive bending moments (bottom reinforcement in tension) than under negative moments (top reinforcement in tension). This fact 
(i.e. the strains on bottom reinforcement under positive bending being larger than the strains in top reinforcement under negative bending) can be actually observed in 6 , although the bottom reinforcement ratio is 1.33 times higher than the top reinforcement ratio. However, the main reason of this behavior in the tests conducted for this study is that the maximum bending moment transferred by the column to the slab was larger under maximum positive displacement (i.e. maximum positive moment on the slab) than under maximum negative displacement (i.e. maximum negative moment on the slab). The bending moment on the columns was calculated from the strains measured by the gages attached to the steel column (see Fig. 2).

The strain difference between steel and surrounding concrete due to the aforementioned loss of adherence can be roughly estimated assuming that: (i) the distance between the centroid of the tension reinforcement and the resultant of the compressive stress in the concrete is approximately $0.9 d$, and (ii) that the stress distribution in the concrete is triangular. On the basis of these assumptions, it was found that the strain difference between top reinforcement and surrounding concrete was about 0.00027 for the seismic simulation with $P A=0.94 g$, and about 0.00037 for the seismic simulation with $\mathrm{PA}=1.1 \mathrm{~g}$.

\subsection{Effective width prediction with formula proposed in past research}

Given the RC slab shown in Fig. 8, whose dimension perpendicular to the direction of the horizontal loading is $l_{2}$, the effective width under this loading is defined as the fictitious width which, supporting a uniform rotation along its whole extension, gives the same displacement in columns than the original slab. The ratio between effective and original widths is usually noted as $\alpha$.

One of the formulae for calculating the effective width $\alpha l_{2}$ is the one proposed by Grossman [9], which is applicable to the specimen tests for this study because it is totally symmetric. The expression is:

$\alpha l_{2}=K_{D}\left[0.3 l_{1}+c_{1} \frac{l_{2}}{l_{1}}+\frac{c_{2}-c_{1}}{2}\right] \frac{d}{0.9 h} K_{F P}$

where $K_{D}$ is a factor considering degradation of stiffness of slabs at various lateral load levels ( 1.1 for the existing lateral drift), $l_{1}$ is the length of span of supports in direction parallel to lateral load, $c_{1}$ is the size of support in direction parallel to lateral load, $c_{2}$ is the size of support in direction transverse to lateral load, $d$ is the effective depth of slab, $h$ is the slab thickness and $K_{F P}$ is a factor that must be taken 1.0 for interior supports, 0.8 for exterior and edge supports, and 0.6 for corner supports). Furthermore, in the case of exterior columns, corrections are made using a factor equal to $\left[I_{3}+\left(I_{2} / 2\right)\right] /$ $l_{2}$, where $l_{3}$ is the distance between the centre line of the column

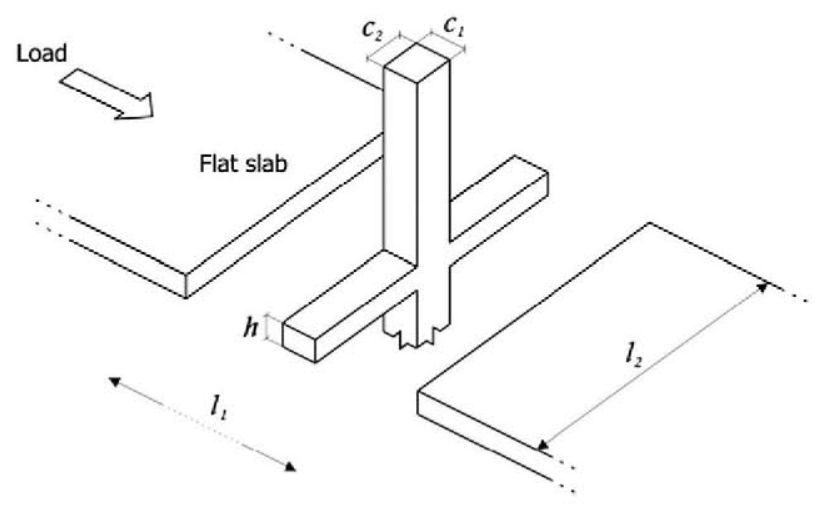

Fig. 8. Parameters of the Grossman's formula. and the parallel edge of the slab. These values for $K_{D}, K_{F P}$ and the exterior column correction factor were suggested by Grossman [9]. Finally, particularizing Eq. (1) for the specimen tested in this study gives:

$$
\begin{aligned}
\alpha l_{2}= & 1.1 \cdot\left[0.3 \cdot 2400+80 \cdot \frac{2400}{2400}+\frac{80-80}{2}\right] \\
& \cdot 0.93 \cdot 0.6 \cdot \frac{110+1200}{2400} \cong 270 \mathrm{~mm}
\end{aligned}
$$

It can be observed that this width $(270 \mathrm{~mm})$ is very small in comparison with the width of the slab where significant strains were measured in the reinforcement during the tests (about $600 \mathrm{~mm}$, as can be seen in Fig. 6). One explanation for this disagreement is that Grossman's formula cannot take into account the effect of the shearheads that form the punching shear reinforcement.

Likewise, applying the formula obtained from experimental calibration of the Pecknold solution by Luo and Durrani [7], which is valid for interior connections with a determined range of variables $\left(0.5 \leqslant c_{1} / c_{2} \leqslant 2.0 ; 0.5 \leqslant l_{1} / l_{2} \leqslant 2.0\right)$, the effective width ratio can be predicted as follows:

$$
\alpha=\frac{1.02\left(\frac{c_{1}}{l_{2}}\right)}{0.05+0.002\left(\frac{l_{1}}{l_{2}}\right)^{4}-2\left(\frac{c_{1}}{l_{1}}\right)^{3}-2.8\left(\frac{c_{1}}{l_{1}}\right)^{2}+1.1\left(\frac{c_{1}}{l_{1}}\right)}
$$

Eq. (2) must be multiplied by a correction factor $\chi$ that accounts for the concrete cracking, which is given by:

$\chi=\left(1-0.4 \cdot \frac{V_{g}}{4 A_{c} \sqrt{f_{c}^{\prime}}}\right)$

where $V_{g}$ is the gravity load shear, $f_{c}^{\prime}$ is the specific concrete strength and $A_{c}$ is the area of concrete section resisting shear transfer. As for $A_{c}$, two possible values can be adopted in reference to Fig. 9 according to $\mathrm{ACI} 318-08$. One possibility is to ignore the shearheads and to take the perimeter as defined by planes parallel and distanced from the column faces half the effective depth of the slab, $A_{c 1}$. The second option, more appropriate for the test model under study, is to incorporate the contribution of the punching shear reinforcement based on C-shape metallic profiles of $60 \mathrm{~mm}$ depth by adopting as perimeter for the critical section that indicated as $A_{c 2}$ in Fig. 9.

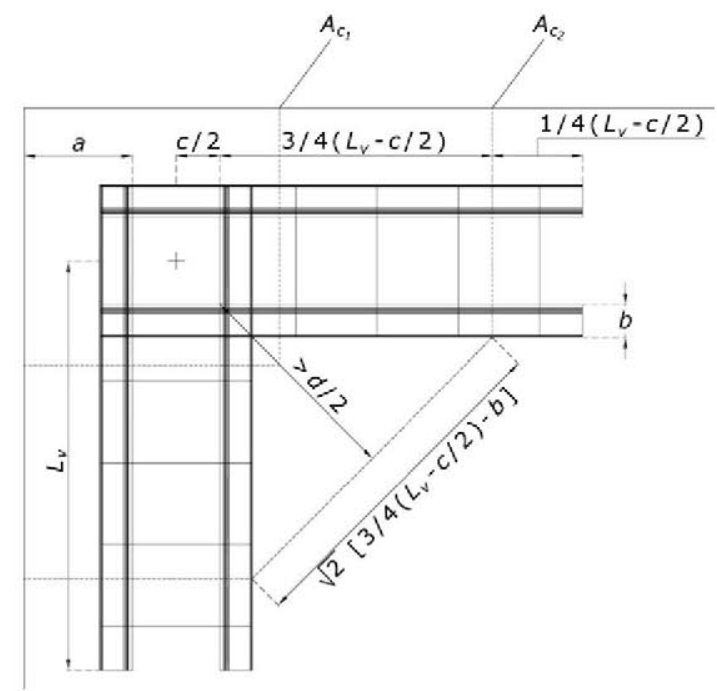

Fig. 9. Perimeter of the critical area for shear transfer. 
Therefore, introducing $A_{c 2}$ and the data of the tested model into Expressions (2) and (3), the following values are obtained:

$$
\begin{aligned}
\alpha & =\frac{1.02\left(\frac{80 \mathrm{~mm}}{2400 \mathrm{~mm}}\right)}{0.05+0.002\left(\frac{2400 \mathrm{~mm}}{2400 \mathrm{~mm}}\right)^{4}-2\left(\frac{80 \mathrm{~mm}}{2400 \mathrm{~mm}}\right)^{3}-2.8\left(\frac{80 \mathrm{~mm}}{2400 \mathrm{~mm}}\right)^{2}+1.1\left(\frac{80 \mathrm{~mm}}{2400 \mathrm{~mm}}\right)} \\
& =0.398
\end{aligned}
$$

$$
\chi=1-0.4 \cdot \frac{4047 \mathrm{lb}}{4 \cdot 28.8 \text { in. } \cdot 4.1 \text { in. } \cdot \sqrt{3408 \mathrm{psi}}} \cong 0.9
$$

The equivalent width ratio given by Eq. (2) is for interior connections. For exterior connections, such as those tested in our study, the authors believe that an additional reduction factor of at least 0.5 should be introduced. Adopting the reduction factor 0.5 , the equivalent width provided by Luo and Durrani's approximation is $430 \mathrm{~mm}$.
Luo and Durrani [8] proposed a further expression for estimating the effective width of exterior connections:

$\alpha l_{2}=\frac{K_{t}}{K_{t}+K_{s}} \cdot l_{2}$

where $K_{t}$ is the torsional stiffness of the torsional members, and $K_{s}$ is the flexural stiffness of the slab considered in the connection.

The main difficulty in applying Eq. (6) is how to include the effect of the shearheads used as punching shear reinforcement. An attempt was made to calculate the torsional stiffness $K_{t}$ with the formula provided by $\mathrm{ACl}$, that is, $K_{t}=\sum 9 E_{c s} C /\left[l_{2}\left(1-c_{2} / l_{2}\right)^{3}\right]$, where $E_{C S}$ is the elastic modulus of the concrete slab and $C$ is a geometric parameter. Since in the type of connection tested in this study there is no edge beam, but two $\mathrm{C}$-shape steel profiles, the formula for estimating $C$ provided by $A C I$, i.e. $C=\sum(1-0.63 x / y) x^{3} y / 3$ cannot be used. Thus, it was decided to estimate $K_{t}$ and $K_{s}$ from finite element models (FEMs) that include composite sections as shown in Fig. 10. Fig. 10a shows the FEM that represents the torsional member that provided $K_{t}$. Fig. $10 \mathrm{~b}$ shows the FEM that represents

(a) Model for calculating $K_{t}$
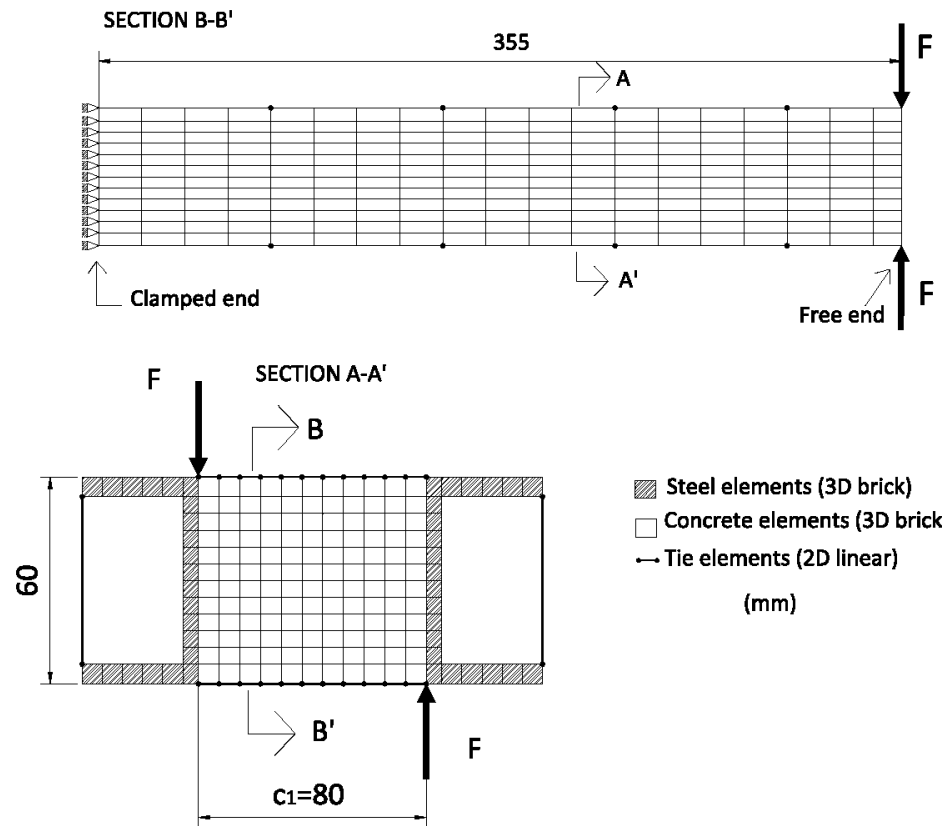

एथ. Steel elements (3D brick)

$\square$ Concrete elements (3D brick)

$\longrightarrow$ Tie elements (2D linear)

(mm)

(b) Model for calculating $K_{s}$
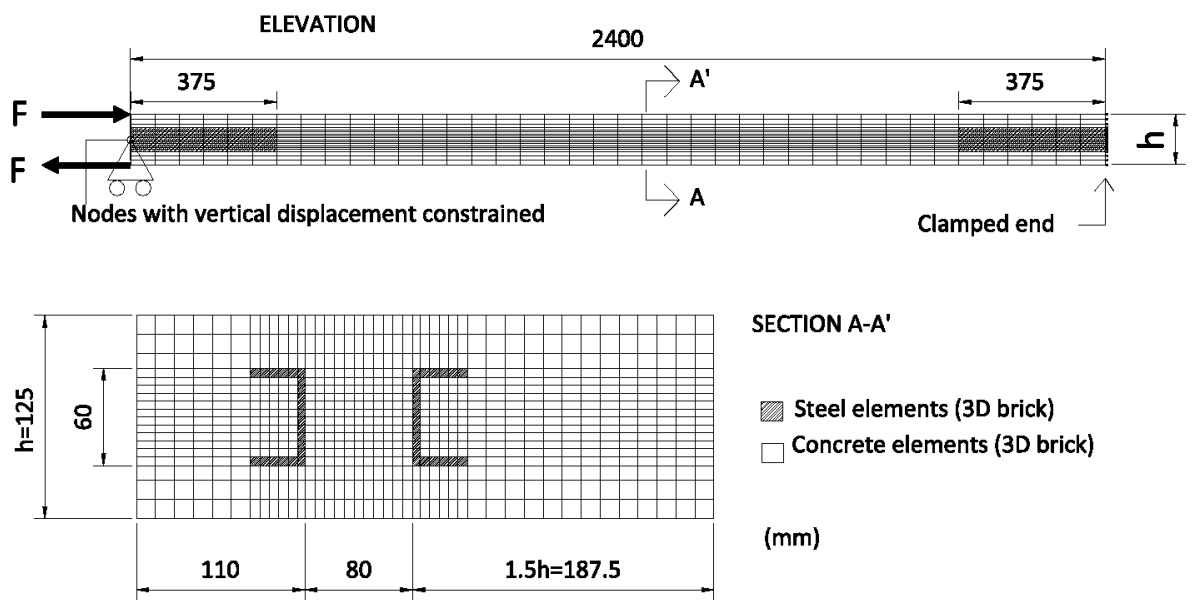

SECTION A-A'

Steel elements (3D brick)

Concrete elements (3D brick)

$(\mathrm{mm})$

Fig. 10. Finite element model used to calculate: (a) $K_{t}$ and (b) $K_{s}$ 
the flexural member that provided $K_{s}$. For the calculation of $K_{t}$, one end of the member (the left end in Fig. 10a) was clamped while the other end was free. For the calculation of $K_{s}$, one end of the member (the right end in Fig. 10b) was clamped, while the other end was free to displace horizontally and rotate, but restrained against vertical displacements. The materials were assumed to remain within the elastic range. The Young modulus assumed for concrete was $2.36 \times 10^{4} \mathrm{~N} / \mathrm{mm}^{2}$ and for steel $2.1 \times 10^{5} \mathrm{~N} / \mathrm{mm}^{2}$. Upper bound values were used in the model assumptions; the concrete was assumed to be uncracked, and thus the initial elastic (upper bound value) Young modulus was used. The channels provided a reasonable increase in stiffness. The stiffness values $K_{t}$ and $K_{s}$ calculated with the steel channels were about $60 \%$ and $50 \%$, respectively, greater than the corresponding values without the steel channels. $K_{t}$ and $K_{s}$ were calculated with a conventional software program, giving $K_{t}=2 \times 10^{8} \mathrm{~N} \mathrm{~mm}$ and $K_{s}=5 \times 10^{8} \mathrm{~N} \mathrm{~mm}$. Substituting these values in Eq. (6) and multiplying by the correction factor that takes into account the concrete cracking gives the following:

$$
\begin{aligned}
\alpha l_{2} \chi & =\frac{2 \times 10^{8} \mathrm{~N} \mathrm{~mm}}{2 \times 10^{8} \mathrm{~N} \mathrm{~mm}+5 \times 10^{8} \mathrm{~N} \mathrm{~mm}} \cdot 2400 \mathrm{~mm} \cdot 0.9 \\
& =617 \mathrm{~mm}
\end{aligned}
$$

This result is very close to the width of the slab where significant strains were measured in the reinforcement during the tests (about $600 \mathrm{~mm}$ as can be seen in Fig. 6).

It is worth noting that the effective width formulae by Grossman [9] and Luo and Durrani [7] were developed for concrete columns. In general, steel columns require smaller sections and have different stiffness in comparison to concrete columns. From the point of view of the size of the section, the authors believe that the formulae by Grossman [9] and by Luo and Durrani [7] are applicable to steel columns as long as the dimensions $c_{1}$ and $c_{2}$ are within the required range of values, i.e. $\left(0.5 \leqslant c_{1} / c_{2} \leqslant 2.0\right.$; $0.5 \leqslant l_{1} / l_{2} \leqslant 2.0$ ) for Luo and Durrani's formulae. However, the different stiffness provided by the steel columns in comparison to the concrete columns could be a contributing factor to the difference measured and effective widths calculated.

\subsection{Proposal for calculation of the effective width of the slab from the test results}

In this section, the effective width of the corner slab-column connection with punching shear reinforcement (shearheads) tested in this study is calculated from the strains measured in the slab reinforcement during the experiments.

Fig. 11 shows a section of one half of the slab, together with the strain distribution of the top and bottom rebars at a given instant of the loading process. The maximum strains in the top and bottom reinforcement are named $\varepsilon_{\max }^{\text {top }}$ and $\varepsilon_{\max }^{b o t}$, respectively, in the figure. The effective width $b_{\text {eff }}$ is defined here as the fictitious width of the slab (measured from the corner in the direction transverse to the lateral load) which, being reinforced with the actual rebars located within $b_{\text {eff }}$ and assuming that all these rebars have the same strain $\varepsilon_{\max }^{\text {top }}$ or $\varepsilon_{\max }^{\text {bot }}$, would have the same flexural capacity as that of the half slab calculated with the actual strain distribution in the rebars.

By applying the above definition, the effective width of the slab can be calculated in a general case as follows. First, the section of one half of the slab is divided into segments of length $b^{\prime}$ as shown in Fig. 12. Each segment $i$ starts at a distance $x_{i}$ measured along the slab perpendicularly to the direction of loading. The area of the upper and lower rebars within each segment, $A_{i}^{\text {top }}$ and $A_{i}^{\text {bot }}$, is taken equal to $A_{i}^{\text {top }}=\int_{x_{i}}^{x_{i}+b^{\prime}} a_{s}^{\text {top }}(x) d x$ and $A_{i}^{\text {bot }}=\int_{x_{i}}^{x_{i}+b^{\prime}} a_{s}^{\text {bot }}(x) d x$ respectively, where $a_{s}^{\text {top }}(x), a_{s}^{\text {bot }}(x)$ denote the areas (per unit length) of the upper and lower reinforcement. The strain of the upper and lower rebars of each segment are estimated from the strain distributions measured during the tests, and they are denoted by $\varepsilon_{s}^{\text {top }}$ and $\varepsilon_{s}^{\text {bot }}$ as shown in Fig. 11. Here, $\varepsilon_{s}^{\text {top }}$ and $\varepsilon_{s}^{\text {bot }}$ denote the average strains within $x_{i}$ and $\left(x_{i}+b^{\prime}\right)$. Assuming a linear strain distribution between $\varepsilon_{s}^{\text {top }}$ and $\varepsilon_{s}^{b o t}$ along the height of the segment, the bending moment $M_{i}$ sustained by each segment is simply obtained from a conventional fiber analysis and the stress-strain relationships obtained from the material tests. In the segments of the slab where bond degradation occurs and $M_{i}$ cannot be calculated using this procedure, the following alternative formula is used:

$M_{i}=A_{s} f_{s} d\left[1-\left(A_{s} f_{s} / 1.7 b^{\prime} f_{c} d\right)\right]$

where $A_{s}$ is the reinforcement area in tension within $b^{\prime}$ and $f_{s}$ is the average stress of the rebars in tension within $b^{\prime}$. Eq. (8) disregards the presence of compression reinforcement and assumes that the distribution of compressive stress on the concrete can be approximated by an equivalent rectangular stress block of $0.85 f_{c}^{\prime}$ whose depth is $\beta_{1} c$. Here, $c$ is the distance from the extreme compression surface to the neutral axis and $\beta_{1}$ is a constant. Following ACI318-08 [18], $\beta_{1}$ is taken equal to 0.85 , since the concrete used for the tests was $f_{c}^{\prime}<27.5 \mathrm{MPa}$. The value of $c$ is obtained by equating

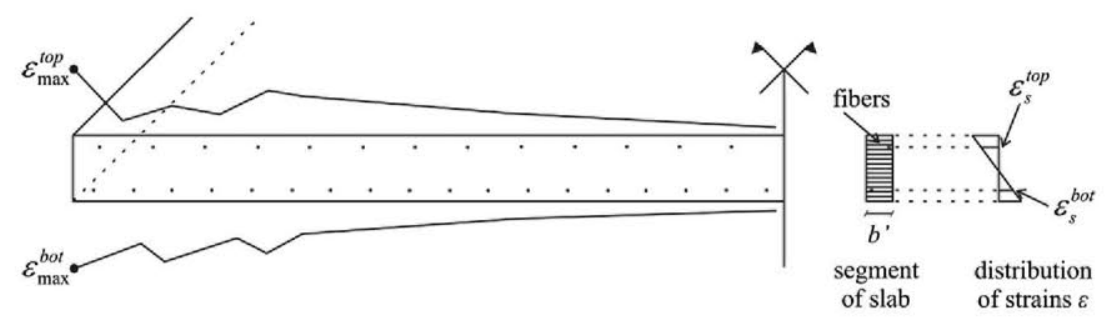

Fig. 11. Assessment of the strain distribution in each segment.

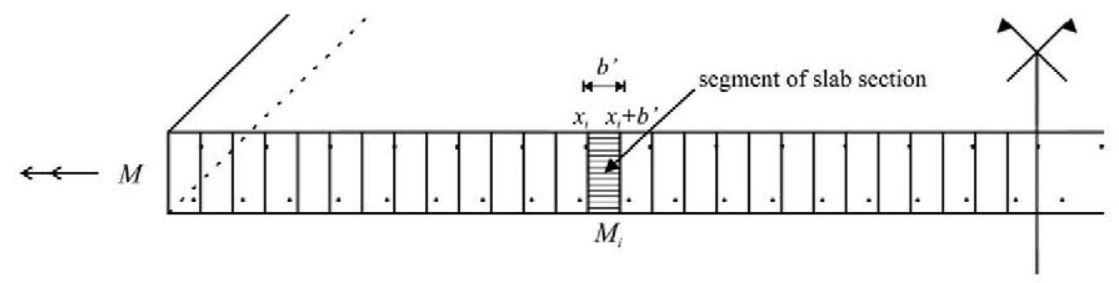

Fig. 12. Explicative scheme of the artificial divisions considered in the slab. 
the compression, $0.85 f_{c}^{\prime} b^{\prime} \beta_{1} c$, and tension, $A_{s} f_{s}$. Once $c$ is determined, Eq. (8) is obtained by taking moments at the centroid of the rectangular concrete stress block.

Then, adding up the bending moments $M_{i}$ along all the segments of the half slab, the total bending moment $M$ is obtained, i.e.: $M=\sum M_{i}$. The total bending moment $M$ calculated in this way was compared with the corresponding moment sustained by the columns (which was calculated from the strains measured with gauges fixed at the end-section of the column), and similar values were obtained (differences less than $11 \%$ ).

Next, a portion of slab of trial width $b_{\text {eff }}$ is considered, whose areas of upper and lower reinforcement are $A_{e j f}^{\text {top }}=\int_{0}^{b_{e f f}} a_{s}^{\text {top }}(x) d x$ and $A_{\text {eff }}^{b o t}=\int_{0}^{b_{\text {eff }}} a_{s}^{\text {bot }}(x) d x$, respectively. The upper and lower rebars of this portion of slab are assumed to have a uniform strain distribution defined by $\varepsilon_{\max }^{\text {top }}$ and $\varepsilon_{\max }^{\text {bot }}$ respectively (see Fig. 11). The bending moment sustained by this portion of slab, $M_{e f f}$, is calculated through a fiber analysis based on the assumption that the strain varies linearly along the height between $\varepsilon_{\max }^{\text {top }}$ and $\varepsilon_{\max }^{b o t}$, just as it did for the portions of width $b^{\prime}$. Through a trial and error iteration procedure, the value of $b_{\text {eff }}$ that makes $M=M_{e f f}$ is determined, and it is taken as the effective width of the corner slab-column connection.

By applying the procedure explained above, the effective width $b_{\text {eff }}$ was computed for each seismic simulation, using the strain distributions at the instant of maximum lateral displacement. The results are shown in Fig. 13. As seen in the figure, $b_{\text {eff }}$ tends to increase with the intensity of the seismic simulation. The rate of this increase with PA is larger while the steel column remains elastic (i.e. for PA less or equal to $0.47 \mathrm{~g}$ ), than after the plastification of the column (i.e. for PA greater than $0.47 \mathrm{~g}$ ). The most important increase in the effective width occurs when PA changes from $0.47 \mathrm{~g}$ to $0.62 \mathrm{~g}$. In this increase of the level of seismic excitation from $0.47 \mathrm{~g}$ to $0.62 \mathrm{~g}$ the loss of adherence phenomena is not yet present. The effective width obtained with the proposed procedure is between the value provided by Grossman (i.e. $270 \mathrm{~mm}$ ) and the upper bound value $(617 \mathrm{~mm}$ ) provided by Luo and Durrani's expression with $K_{t}$ and $K_{s}$ estimated using Finite Element Modeling.

It is worth noting that between the onset of yielding at the outermost fibers of the section of the steel column (which occurred in the seismic simulation corresponding to $0.47 \mathrm{~g}$ ), and the full plastification of the section, the bending moment on the column increases. Also, after plastification, the bending moment on the column can still increase due to strain hardening effects of the material. These two aspects explain why the maximum strains and the calculated effective widths increase with increasing values of applied acceleration.

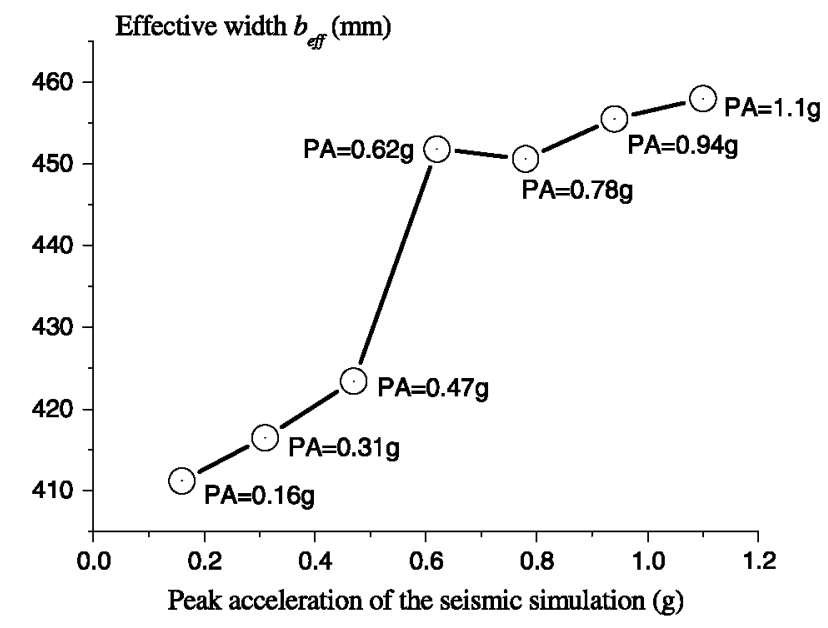

Fig. 13. Effective width calculated from the test results by applying the proposed method.

\section{Conclusions}

This paper describes experimental investigation of the effective width of RC corner flat slab-column connections with shearheads (steel C-shapes) as punching reinforcement, subjected to realistic seismic loadings through dynamic shaking table tests. It is found that the prediction of the effective width has to take into account the differences of rigidity inside the slab due to the presence of steel profiles that constitute the punching shear reinforcement. Owing to this fact, important differences are observed between the results of the tests conducted in this study and the predictions provided by the formula proposed in the literature. In particular, it is found that if the expression proposed by Luo and Durrani for exterior connections is used in combination with a precise evaluation of the torsional stiffness of the shearheads, the effective width predicted using Luo and Durrani's formulae is very close to the width of the slab where significant strains were measured in the reinforcement during the tests.

The paper also puts forth a method for estimating the effective width from the strains in the rebars measured during the tests, based on the equivalence of flexural capacity. By analyzing the evolution through consecutive seismic simulations of increasing intensity, it is found that the effective width tends to increase with increasing values of the peak acceleration applied to the structure. This increase is limited (or even slowed down) by the loss of adherence between the reinforcing steel and the surrounding concrete induced by the strain reversals caused by cyclic loading. Further experimental work must be undertaken to fully clarify the influence of the embedded steel profiles on the effective width of flat slabs subjected to earthquake-type dynamic loading.

\section{Acknowledgements}

This research was funded by the local government of Spain, Consejeria de Innovación, Ciencia y Tecnología (Project P07-TEP02610) and by the European Union (Fonds Européen de Dévelopment Régional). We also express special thanks to the Spanish Ministry of Education for Grant Number FPU-AP2009-3475.

\section{References}

[1] Corley WG, Jirsa Jo. Equivalent frame analysis for slab design. ACl Struct J 1970;67:875-84.

[2] Pecknold DA. Slab effective width for equivalent frame analysis. ACI Struct J 1975:4:135-7.

[3] Allen F, Darvall P. Lateral load equivalent frame. ACI Struct J 1977;74(7):294-9.

[4] Vanderbilt DM. Equivalent frame analysis of unbraced reinforced concrete buildings for static lateral loads. Civil Engineering Department, Colorado State University, Structural research report; 1981. p. 36.

[5] Hwan SJ, Moehle JP. An experimental study of flat-plate structures under vertical and lateral loads. Report no. UCB/SEMM-90/11. Department of Civil Engineering, University of California, Berkeley; 1990. p. 271.

[6] Farhey DN, Adin MA, Yankelevsky DZ. RC flat slab-column subassemblages under lateral loading. J Struct Eng, ASCE 1993;119(6):1903-16.

[7] Luo YH, Durrani AJ. Equivalent beam model for flat-slab buildings - part I: interior connections. ACI Struct J 1995;92(1):115-24.

[8] Luo YH, Durrani AJ. Equivalent beam model for flat-slab buildings - part II: exterior connections. ACI Struct J 1995;92(2):250-7.

[9] Grossman JS. Verification of proposed design methodologies for effective width of slabs in slab-column frames. ACI Struct J 1997;94(2):181-96.

[10] Kim HS, Lee DG. Efficient analysis of flat slab structures subjected to lateral loads. Eng Struct 2005;27(2):251-63.

[11] Shin M, Lafave JM. Reinforced concrete edge beam-column-slab connections subjected to earthquake loading. Mag Concr Res 2004;56(5):273-91.

[12] Dovich LM, Wight JK. Effective slab width model for seismic analysis of flat slab frames. ACI Struct J 2005;102(6):868-75.

[13] Otani S. Effect of strain rate on steel and concrete. In: Proceedings of the Japan Concrete Institute, vol. 21; 1986. p. 23-33.

[14] Building code requirements for structural concrete (ACI318-95) and commentary (ACl318R-95). American Concrete Institute Committee 318, Farmington Hills, MI. 
[15] Building code requirements for structural concrete (ACI318-99) and commentary (ACI318R-99). American Concrete Institute Committee 318 Farmington Hills, MI.

[16] Building code requirements for structural concrete ( $\mathrm{ACl} 318-02)$ and commentary (ACl318R-02). American Concrete Institute Committee 318 Farmington Hills, MI.

[17] Building code requirements for structural concrete (ACl318-05) and commentary (ACl318R-05). American Concrete Institute Committee 318, Farmington Hills, MI.

[18] Building code requirements for structural concrete (ACl318-08) and commentary (ACl318R-08). American Concrete Institute Committee 318 , Farmington Hills, MI
[19] Eurocode 2: design of concrete structures - part I: general rules and rules for buildings. European Committee for Standardisation (CEN), Brussels, ENV 1992 1-1.

[20] NCSE-02 Norma de Construcción Sismorresistente Parte general y edificación. Spanish Ministry of Construction, Madrid; 2002.

[21] CTE Código Técnico de la Edificación. Spanish Ministry of Housing, Madrid; 2006.

[22] EHE-08 Instrucción de Hormigón Estructural, Comisión Permanente del Hormigón. Spanish Ministry of Construction, Madrid; 2008.

[23] Quintero-Febres CG, Wight JK. Experimental study of reinforced concrete interior wide beam-column connections subjected to lateral loading. $\mathrm{ACl}$ Struct J 2001;98(4):572-82. 